\title{
Adsorption of inorganic ions from aqueous solutions using mineral sorbent - tripoli
}

\author{
Tatyana Yurmazova ${ }^{1}$, Nina Shakhova ${ }^{1, *}$, and Hoang Tran Tuan ${ }^{1}$ \\ ${ }^{1}$ Tomsk Polytechnic University, Tomsk, Russia
}

\begin{abstract}
The present research considers the adsorption of $\mathrm{H}_{2} \mathrm{AsO}_{4}{ }^{-}$, $\mathrm{CrO}_{4}{ }^{2-}, \mathrm{Ni}^{2+}, \mathrm{Fe}^{3+}$ ions from their aqueous solutions by mineral sorbent tripoli. Tripoli was characterized by different physico-chemical methods such as X-ray phase analysis, inductively coupled plasma atomic emission spectrometry, method of thermal desorption of nitrogen. Contact time, specific surface area, specific pore volume and surface charge of tripoli have been determined. The effect of tripoli surface area modification by iron (III) oxide-hydroxide on tripoli sorption capacity for the arsenic anions has been investigated. The maximum adsorption was found to occur within 30 minutes of contact time. Different models including the pseudofirst-order kinetic and the pseudo-second-order kinetic equations were used to analyse kinetic data. All the models being considered, it has been stated that the pseudo-second-order kinetic model is the most appropriate to describe the adsorption behaviour of $\mathrm{Fe}^{3+}$ ions on tripoli. The adsorption has been explained in terms of Langmuir and Freundlich isotherms. Based on values of correlation coefficients, $\mathrm{H}_{2} \mathrm{AsO}_{4}{ }^{-}, \mathrm{CrO}_{4}{ }^{2-}, \mathrm{Ni}^{2+}, \mathrm{Fe}^{3+}$ sorption isotherm data were better fitted by Langmuir model. It has been detected that the modification of mineral sorbent (tripoli) leads to the increase in $\mathrm{H}_{2} \mathrm{AsO}_{4}^{-}$adsorbing capacity of tripoli. In general, the results indicated that tripoli can be an efficient low-cost sorbent for removing $\mathrm{H}_{2} \mathrm{AsO}_{4}^{-}, \mathrm{Ni}^{2+}$, $\mathrm{Fe}^{3+}$ ions from aqueous solutions.
\end{abstract}

\section{Introduction}

Existing methods for water purification from $\mathrm{H}_{2} \mathrm{AsO}_{4}{ }^{-}, \mathrm{CrO}_{4}{ }^{2-}, \mathrm{Ni}^{2+}, \mathrm{Fe}^{3+}$ ions are based on processes of oxidation, sedimentation, coagulation and membrane technologies. Nevertheless, they cannot be used to reduce concentrations of these ions to permissible levels. Nowadays sorption method is generally given preference over other water purification techniques due to its high efficiency, easy handling; besides, it is environmentally friendly [1-12]. Literature review [1-7] showed that mineral sorbents are cheap and available material capable to remove heavy metal ions from industrial wastewater.

Since mineral sorbents hardly ever have appropriate adsorption properties, they are to be chemically or physically modified [12-15]. Due to modification the maximum adsorption capacity of mineral sorbent increases severalfold. Thus, the search for low-cost

\footnotetext{
* Corresponding author: nina.b.shakhova@gmail.com
} 
and effective adsorbents has become the focus of attention for many studies. Bannova et al. [12] studied the conditions and parameters of modification of tripoli in order to obtain a hydrophobic sorbent. Anisimov et al. [13] determined that synthetic chemically modified terra silica (complex sorbent) effectively decreases water hardness. In the papers $[14,15]$ the influence of ultrasonic treatment as well as thermal and microwave modification of tripoli were discussed. However, mechanism of adsorption has not been the subject of a detailed analysis.

The present study is focused upon adsorption of $\mathrm{H}_{2} \mathrm{AsO}_{4}{ }^{-}, \mathrm{CrO}_{4}{ }^{2-}, \mathrm{Ni}^{2+}, \mathrm{Fe}^{3+}$ ions from their aqueous solutions by mineral sorbent tripoli. The effect of various parameters affecting sorption behaviour such as contact time, specific surface area, tripoli surface charge, modification of the surface area of sorbent has been investigated to better understand the adsorption process and ways of possible usage of the mineral sorbent (tripoli) for wastewater purification.

\section{Experimental studies}

\subsection{Sorbent}

Low-cost locally available tripoli (Zikeevsk deposit, Russia) was selected as a natural mineral sorbent. The chemical composition of tripoli was defined by inductively coupled plasma atomic emission spectrometry using iCAP 6300 Duo ThermoScientific (USA). Xray phase analysis with a Shimadzu XRD-7000 $\mathrm{CuK}_{\alpha}$-radiation diffractometer (Germany) was used to identify phase composition of tripoli. The specific surface area $(\mathrm{S})$ of tripoli was determined by thermal desorption of nitrogen using specific surface analyser Sorbi-3M (Russia).

\subsection{Adsorption studies}

All chemicals used in this research were of analytical grade. To determine the optimal time required for reaching the sorption equilibrium, static adsorption was induced, with different contact time being considered. Equal quantity of $0.05 \mathrm{~g}$ of dry adsorbent was mixed with $50 \mathrm{~mL}$ of the solution with equal initial concentration of $\mathrm{Fe}^{3+}$ ions $20 \mathrm{mg} \cdot \mathrm{L}^{-1}$ over the periods corresponding to different contact time; and then the mixture was centrifuged with the centrifuge «Allegra 64R» (USA) for $10 \mathrm{~min}$ at $10000 \mathrm{rpm}$. The concentration of the residual $\mathrm{Fe}^{3+}$ ions in the solution was measured using spectrophotometer «ApelPD-303UV» (Japan).

The static adsorption of $\mathrm{Fe}^{3+}, \mathrm{Ni}^{2+}, \mathrm{CrO}_{4}{ }^{2-}, \mathrm{H}_{2} \mathrm{AsO}_{4}{ }^{-}$ions on tripoli was investigated using $100 \mathrm{~mL}$ flasks where $50 \mathrm{~mL}$ of $\mathrm{Fe}^{3+}, \mathrm{Ni}^{2+}, \mathrm{CrO}_{4}{ }^{2-}, \mathrm{H}_{2} \mathrm{AsO}_{4}^{-}$ions solution of different initial concentrations and $0.05 \mathrm{~g}$ of tripoli were added at temperature of $25^{\circ} \mathrm{C}$. The initial concentration of adsorbate ions in the solutions was in the range of $10-100 \mathrm{mg} \cdot \mathrm{L}^{-1}$.

In $30 \mathrm{~min}$, after the sorption equilibrium having been reached, the adsorbent was separated from the solution by spinning for $10 \mathrm{~min}$ at $10000 \mathrm{rpm}$ and the equilibrium concentration was measured. The equilibrium concentration of $\mathrm{Fe}^{3+}, \mathrm{Ni}^{2+}, \mathrm{CrO}_{4}{ }^{2-}, \mathrm{H}_{2} \mathrm{AsO}_{4}{ }^{-}$ ions was determined by chemical and physico-chemical methods. The equilibrium concentration of $\mathrm{Fe}^{3+}, \mathrm{Ni}^{2+}, \mathrm{CrO}_{4}{ }^{2-}, \mathrm{H}_{2} \mathrm{AsO}_{4}{ }^{-}$ions was measured using UV/visible spectrometer with appropriate reagents.

Equilibrium adsorption capacity of the adsorbent $\mathrm{A}_{e}\left(\mathrm{mg} \cdot \mathrm{g}^{-1}\right)$ was calculated by the formula: 


$$
A_{e}=\frac{\left(C_{i}-C_{e}\right) \cdot V}{m}
$$

Where, $A_{e}$ is the adsorption capacity, $\mathrm{mg} \cdot \mathrm{g}^{-1} ; C_{i}$ is the initial concentration of ions in the solution, $\mathrm{mg} \cdot \mathrm{L}^{-1} ; C_{e}$ is the equilibrium concentration of ions, $\mathrm{mg} \cdot \mathrm{L}^{-1} ; V$ is the volume of ions solution used, $\mathrm{mL} ; m$ is the mass of adsorbent used, $\mathrm{g}$.

\subsection{Effect of tripoli surface charge on adsorption}

Indicator method was applied to detect the influence of the tripoli surface charge on the adsorption properties. Methylene blue (monovalent cationic dye) and eosin (monovalent an anionic dye) were used as indicators of tripoli surface charge. The static adsorption of methylene blue and eosin was analysed.

$\mathrm{C}_{16} \mathrm{H}_{18} \mathrm{ClN}_{3} \mathrm{~S} \cdot \mathrm{HCl} \rightarrow\left[\mathrm{C}_{16} \mathrm{H}_{18} \mathrm{ClN}_{3} \mathrm{~S}\right] \mathrm{H}^{+}+\mathrm{Cl}^{-}$- methylene blue, a cationic dye; (Russia)

$\mathrm{Na}_{2}\left[\mathrm{C}_{20} \mathrm{H}_{6} \mathrm{O}_{5} \mathrm{Br}_{4}\right] \rightarrow 2 \mathrm{Na}^{+}+\left[\mathrm{C}_{20} \mathrm{H}_{6} \mathrm{O}_{5} \mathrm{Br}_{4}\right]^{2-}$ - eosin, an anionic dye (Russia).

Using Zetasizer Nano ZS instrument (Germany), the value of initial tripoli surface $\zeta$ potential was measured as well as the value of surface $\zeta$-potential of tripoli, with different amounts of adsorbed methylene blue being added.

\subsection{Effect of chemical modification of tripoli surface area on adsorptive capacity}

To enhance the adsorption properties of mineral sorbent the surface area of tripoli was subjected to chemical modification by iron (III) oxide-hydroxide $(\mathrm{FeO}(\mathrm{OH}))$.

The experiment on chemical modification of tripoli was carried out, with tripoli being treated with the ferric chloride (III) solution and then sodium hydroxide solution at temperature of $50^{\circ} \mathrm{C}$. In each test $10 \mathrm{~g}$ of tripoli were added to the solution of ferric chloride (III) of different concentration $\left(20-100 \mathrm{mg} \cdot \mathrm{L}^{-1}\right)$, with the contact time being 2 hours. Then the solution was decanted and tripoli with adsorbed $\mathrm{Fe}^{3+}$ ions was treated with sodium hydroxide at temperature of $50^{\circ} \mathrm{C}$. After that the solution was decanted again, and tripoli modified by iron (III) oxide-hydroxide $(\mathrm{FeO}(\mathrm{OH}))$ was washed with distilled water to reach pH $6.5-7.2$. Finally, the samples were filtered and dried.

\section{Results and discussion}

Based on the results of inductively coupled plasma atomic emission spectrometry, the tripoli is composed of $\mathrm{SiO}_{2}(89 \%), \mathrm{Al}_{2} \mathrm{O}_{3}(3.9 \%), \mathrm{Fe}_{2} \mathrm{O}_{3}(2.38 \%), \mathrm{CaO}(0.69 \%), \mathrm{MgO}$ $(0.44 \%)$, other components account for $3.59 \%$. X-ray diffractogram of tripoli is given in figure 1 .

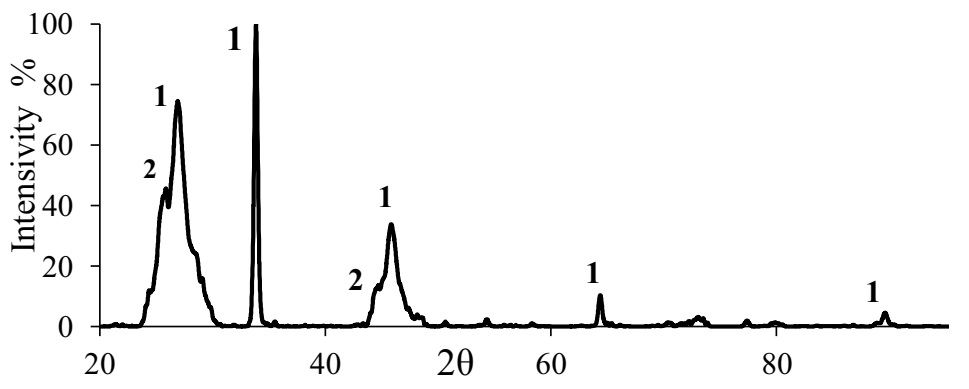

Fig. 1. XRD patterns of tripoli $1-\beta$ quartz, $2-\beta$ cristobalite. 
The diffractogram of tripoli showed that the dominant phase is $\mathrm{SiO}_{2}$ ( $\beta$ quartz), with $\beta$ cristobalite being present. The specific surface area and specific pore volume of tripoli were $94.6 \mathrm{~m}^{2} \cdot \mathrm{g}^{-1}$ and $0.011 \mathrm{sm}^{3} \cdot \mathrm{g}^{-1}$, respectively.

The static adsorption of $\mathrm{Fe}^{3+}$ ions on tripoli was studied to determine the optimal time required for reaching the sorption equilibrium. The effect of contact time on the adsorption of $\mathrm{Fe}^{3+}$ ions by tripoli can be observed in figure 2 . It has been indicated that the adsorption of $\mathrm{Fe}^{3+}$ ions tends to increase with time and attains the maximum value over $30 \mathrm{~min}$ and then remains constant. Therefore, all further adsorption experiments were carried, with this reference time being considered. The kinetics of the adsorption of $\mathrm{Fe}^{3+}$ ions on tripoli was analyzed by using pseudo-first-order and pseudo-second-order kinetic models [4, 5]. The linear plot of kinetics based on pseudo-second-order model and the correlation coefficient are shown in figure 3.

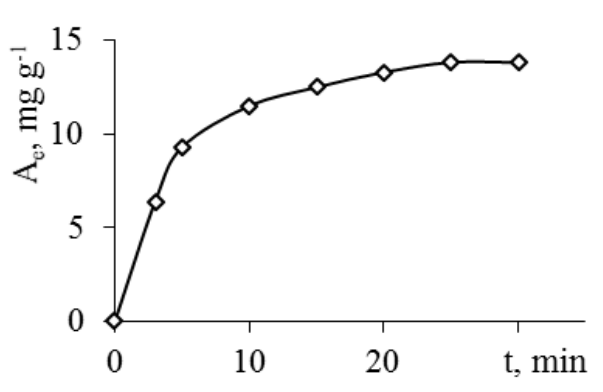

Fig. 2. The kinetics of $\mathrm{Fe}^{3+}$ ion adsorption on tripoli.

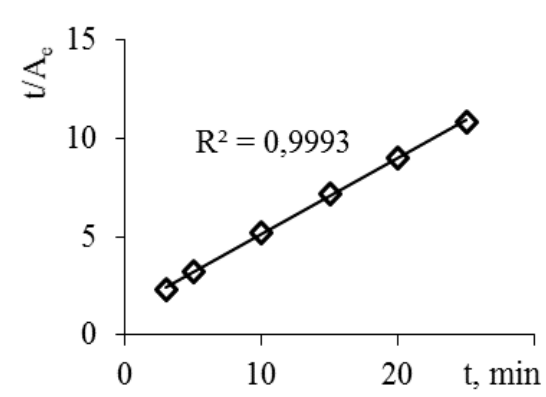

Fig. 3. Pseudo-second-order kinetic plot for the adsorption of $\mathrm{Fe}^{3+}$ on tripoli.

It can be observed that the values of the correlation coefficient for both the pseudo-firstorder and pseudo-second order models are close to unity. However, the curve-fitting plots of $t / A_{e}$ versus $t$ give a straight line, with the correlation coefficient close to $1\left(\mathrm{R}^{2}=0.999\right)$ confirming the applicability of the pseudo-second-order equation. It can be assumed that the adsorption rate is determined not only by the speed of diffusion processes, but also by the rate of chemical interaction between the sorbate and the sorbent. The adsorption of $\mathrm{H}_{2} \mathrm{AsO}_{4}{ }^{-}, \mathrm{CrO}_{4}{ }^{2-}, \mathrm{Ni}^{2+}, \mathrm{Fe}^{3+}$ ions using tripoli is shown in figure 4 .

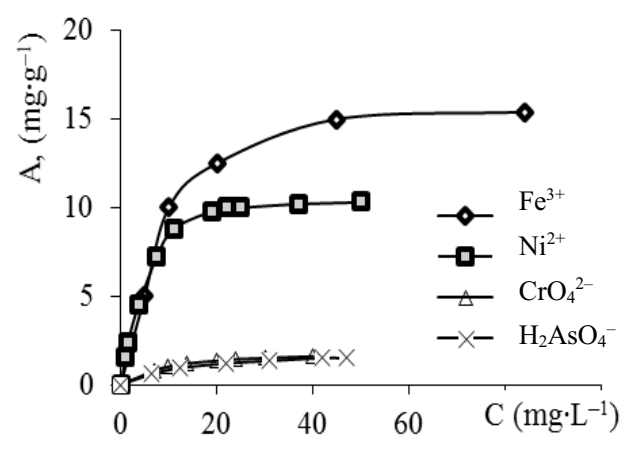

Fig. 4. Adsorption isotherm of $\mathrm{H}_{2} \mathrm{AsO}_{4}{ }^{-}, \mathrm{CrO}_{4}{ }^{2-}$, $\mathrm{Ni}^{2+}, \mathrm{Fe}^{3+}$ on tripoli.

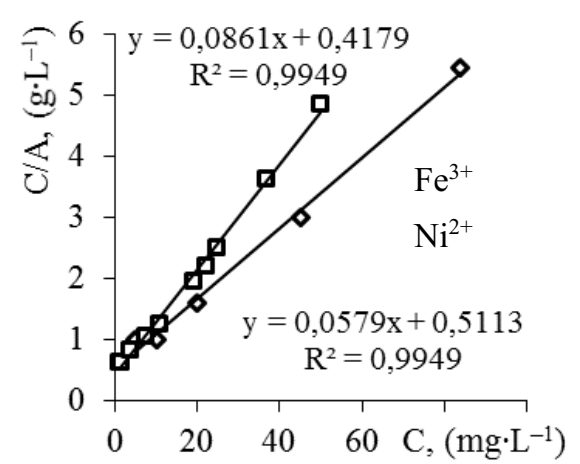

Fig. 5. Lengmuir plots for the adsorption of $\mathrm{Ni}^{2+}, \mathrm{Fe}^{3+}$ on tripoli. 
From figure 4, it can be observed that the uptake of $\mathrm{Ni}^{2+}, \mathrm{Fe}^{3+}$ ions on tripoli is much better than adsorption of $\mathrm{H}_{2} \mathrm{AsO}_{4}^{-}, \mathrm{CrO}_{4}{ }^{2-}$. The capacity of tripoli to adsorb $\mathrm{H}_{2} \mathrm{AsO}_{4}{ }^{-}$, $\mathrm{CrO}_{4}{ }^{2-}, \mathrm{Ni}^{2+}, \mathrm{Fe}^{3+}$ ion is shown in table 1 .

The adsorption isotherm data were analyzed in terms of Langmuir and Freundlich isotherms (figure 5). Langmuir and Freundlich isotherms are the most widely used models for solid-liquid adsorption [4-6]. Based on the values of the correlation coefficients, it can be inferred that the equilibrium adsorption data were better described by the Langmuir adsorption model. The Langmuir model assumes that each adsorbate molecule is located at specific homogenous sites within the adsorbent. Thus, it predicts the formation of a monolayer of the adsorbate on the homogenous adsorbent surface and does not consider surface heterogeneity of the adsorbent.

Table 1. Parameters for ion adsorption on tripoli.

\begin{tabular}{|c|c|c|c|c|}
\hline Ions & $\mathbf{F e}^{3+}$ & $\mathbf{N i}^{{ }^{++}}$ & $\mathbf{C r O}_{4}{ }^{2-}$ & $\mathbf{H}_{2} \mathbf{A s O}_{4}{ }^{-}$ \\
\hline $\mathrm{A}_{\infty}\left(\mathrm{mg} \cdot \mathrm{g}^{-1}\right)$ & 17.27 & 11.614 & 1.9988 & 1.97 \\
\hline $\mathrm{K}\left(\mathrm{L} \cdot \mathrm{mg}{ }^{-1}\right)$ & 0.113 & 0.206 & 0.102 & 0.07 \\
\hline
\end{tabular}

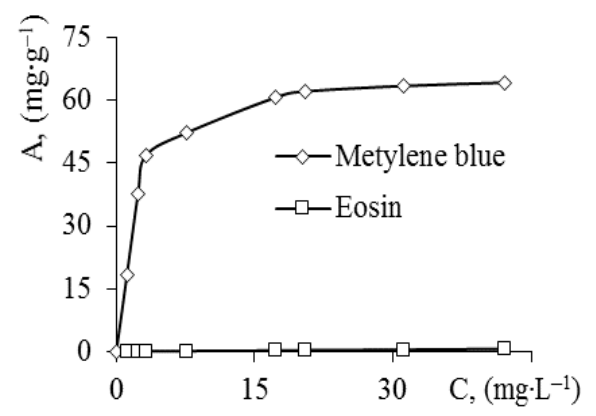

Fig. 6. Adsorption isotherm of methylene blue and eosin on tripoli.

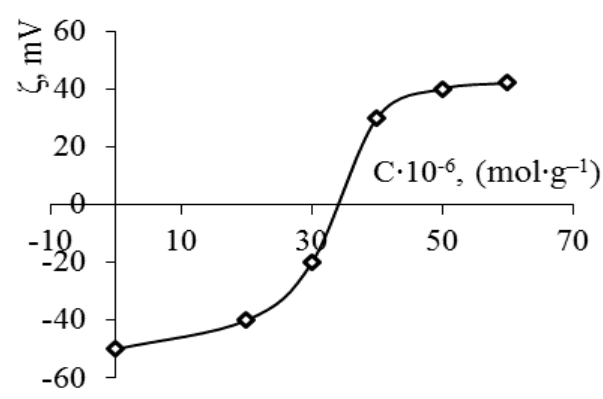

Fig. 7. The dependence of the tripoli $\zeta$-potential on the amount of adsorbed methylene blue.

Figure 6 shows the effect of the tripoli surface charge on the adsorption properties with the use of indicator method. Based on these data, it can be seen that methylene blue uptake by tripoli is much better than eosin uptake. This can be explained by the fact that the tripoli active sites are negatively charged.

The investigation of the value of initial tripoli surface $\zeta$-potential, as well as the value of surface $\zeta$-potential of tripoli with different amounts of adsorbed methylene blue (figure 7) indicates that $\zeta$-potential behavior is described by a curve passing through a zero value. When methylene blue being adsorbed, both the value and $\zeta$-potential charge change. This proves that charge interactions between the adsorbent and adsorbate are of great significance.

In this study, the chemical modification of mineral sorbent (tripoli) is performed to enhance the capacity of tripoli to adsorb $\mathrm{H}_{2} \mathrm{AsO}_{4}^{-}$ions. Arsenic concentration above acceptable standards $\left(0.05 \mathrm{mg} \cdot \mathrm{L}^{-1}\right)$ in drinking water has been detected in many countries and, thus, the removal of arsenic from drinking water is a global issue [1-3]. Iron (III) oxide-hydroxide $(\mathrm{FeO}(\mathrm{OH}))$ was used to modify the tripoli surface area due to low solubility of ferric arsenate $\left(\mathrm{K}_{s p}\left(\mathrm{FeAsO}_{4}\right)=5.8 \cdot 10^{-21}\right)$ and non-toxicity of $\mathrm{Fe}^{3+}$ ions.

The values of specific surface area and specific pore volume of initial tripoli and modified tripoli are given in table 2. As shown in table 2, the studied adsorbents are characterized by low pore volume and high specific surface area. Therefore, we can assume that in case of water treatment with tripoli no intraparticle diffusion processes occur, which, in its turn, will speed up sorption equilibrium attainment. 
Table 2. Characterization of adsorbent.

\begin{tabular}{|l|l|l|l|}
\hline Adsorbent & $\begin{array}{l}\text { Concentration of } \\
\text { iron ions, } \mathbf{( \% )}\end{array}$ & $\begin{array}{l}\text { Specific surface } \\
\text { area, }\left(\mathbf{m}^{\mathbf{2}} \mathbf{g}^{-\mathbf{1}}\right)\end{array}$ & $\begin{array}{l}\text { Specific pore } \\
\text { volume, }\left(\mathbf{s m}^{\mathbf{3}} \mathbf{g}^{-\mathbf{1}}\right)\end{array}$ \\
\hline Tripoli & 0.38 & 94.6 & 0.011 \\
\hline $\begin{array}{l}\text { Tripoli modified by } \mathrm{FeO}(\mathrm{OH}) \\
\text { (sample 1) }\end{array}$ & 0.96 & 98.8 & 0.042 \\
\hline $\begin{array}{l}\text { Tripoli modified by } \mathrm{FeO}(\mathrm{OH}) \\
\text { (sample 2) }\end{array}$ & 2.8 & 114 & 0.052 \\
\hline
\end{tabular}

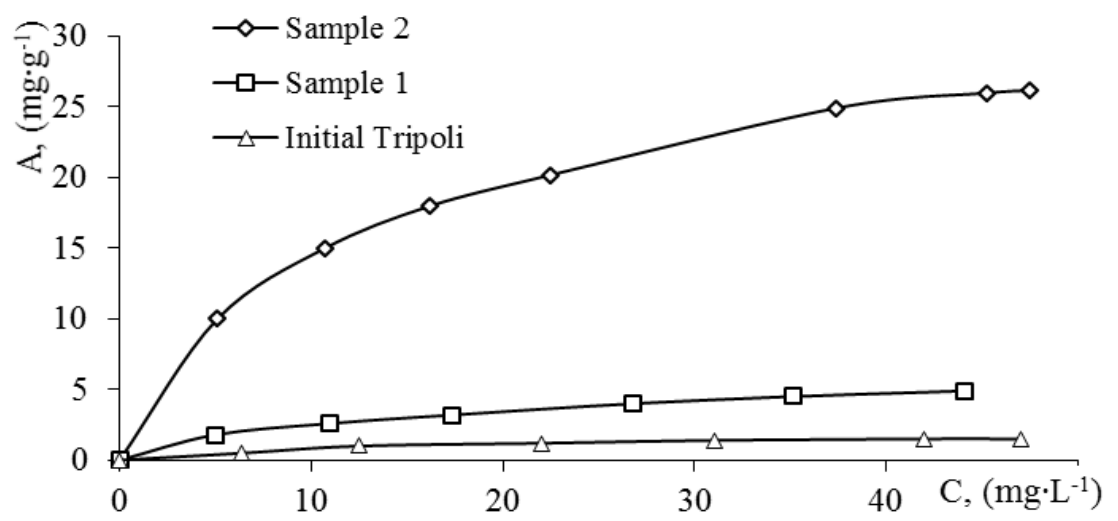

Fig. 8. Adsorption isotherms of $\mathrm{H}_{2} \mathrm{AsO}_{4}{ }^{-}$ions on initial tripoli and tripoli modified by $\mathrm{FeO}(\mathrm{OH})$.

Adsorption isotherms of $\mathrm{H}_{2} \mathrm{AsO}_{4}^{-}$ions on modified tripoli are shown in figure 8. From this figure, it can be observed that static absorption of $\mathrm{H}_{2} \mathrm{AsO}_{4}^{-}$ions on modified tripoli is much better than the uptake of $\mathrm{H}_{2} \mathrm{AsO}_{4}{ }^{-}$ions on initial tripoli. An increase in the adsorption capacity of tripoli modified by $\mathrm{FeO}(\mathrm{OH})$ is due to formation of insoluble ferric arsenate with extremely low value of the solubility product constant $\left(\mathrm{K}_{s p}=5.8 \cdot 10^{-21}\right)$. From figure 8 , it can be seen that maximum adsorption capacity of $\mathrm{H}_{2} \mathrm{AsO}_{4}^{-}$ions increases severalfold. The maximum adsorption capacity of $\mathrm{H}_{2} \mathrm{AsO}_{4}^{-}$ions increased with the increase in the amount of iron (III) oxide-hydroxide in modified tripoli. The maximum adsorption capacity of tripoly for $\mathrm{H}_{2} \mathrm{AsO}_{4}{ }^{-}$ions is $\mathrm{A}_{\infty}=33.33 \mathrm{mg} \cdot \mathrm{g}^{-1}$ which is equivalently high level.

To assess the stability of the compounds formed as a result of arsenic ions sorption on tripoli the desorption process of arsenic ions in distilled water was carried out. Periodical sampling during a month showed that the arsenic concentration does not exceed the level of trace concentrations. Sediments obtained as a result of arsenic ions sorption on tripoli belong to the class of low-solubility compounds which are suitable for disposal [11].

\section{Conclusion}

1. The adsorption of $\mathrm{H}_{2} \mathrm{AsO}_{4}^{-}, \mathrm{CrO}_{4}{ }^{2-}, \mathrm{Ni}^{2+}, \mathrm{Fe}^{3+}$ ions from their aqueous solutions by mineral sorbent tripoli has been studied. It has been stated that the maximum adsorption occurs within $30 \mathrm{~min}$ of contact time. Based on high correlation coefficient value, the sorption equilibrium data for $\mathrm{Fe}^{3+}$ ions were better fitted to the pseudo-second-order kinetic model.

2. The maximum adsorption capacity of tripoli for $\mathrm{H}_{2} \mathrm{AsO}_{4}{ }^{-}, \mathrm{CrO}_{4}{ }^{2-}, \mathrm{Ni}^{2+}, \mathrm{Fe}^{3+}$ ions has been determined. It has been deduced that the sorption of $\mathrm{H}_{2} \mathrm{AsO}_{4}{ }^{-}, \mathrm{CrO}_{4}{ }^{2-}, \mathrm{Ni}^{2+}, \mathrm{Fe}^{3+}$ ions was better described by the Langmuir absorption model. This means that each adsorbate 
molecule is located at specific homogenous sites within the adsorbent, with a monolayer of the adsorbate on the adsorbent surface being formed.

3. The study has indicated that tripoli can be an effective adsorbent for the removal of $\mathrm{Ni}^{2+}, \mathrm{Fe}^{3+}$ ions from aqueous solutions. This is due to the fact that surface charge of tripoli is negative, which is confirmed by recharging of the surface in course of methylene blue sorption by tripoli.

4. This research suggests that the mineral sorbent - tripoli can be effectively used as an adsorbent for the removal of $\mathrm{Ni}^{2+}, \mathrm{Fe}^{3+}$ ions from aqueous solutions as well as tripoli modified by $\mathrm{FeO}(\mathrm{OH})$ can be effectively used in the removal of $\mathrm{H}_{2} \mathrm{AsO}_{4}{ }^{-}$ions in different concentrations. The research can be carried on further to study application of tripoli to water treatment.

\section{References}

1. G. Saveliev, T. Yurmasova, N. Shakhova Bulletin of Higher Sch. Chem. and chem. technology 53, 36-39 (2011) (in Russian)

2. M. Dinesh, U. Charles, Jr. Pittman J. of Hazard. Mater. 142, 1-53 (2007).

3. A. Malik, Z. Khan, Q. Mahmood, S. Nasreen et al. J. of Hazard. Mater. 168, 1-12 (2009)

4. K. Nebaghaa, K. Ziata, L. Rghiouib, M. Khayetd, M. Saidia, K. Aboumariaf, A. Hourchg, S. Sebtih J. Mater. Environ. Sci. 6, 3022-33 (2015)

5. K. Nebaghaa, K. Ziata, L. Rghiouib, M. Khayetd, A. Najif, M. Saidia J. Mater. Environ. Sci. 6, 2694-2702 (2015)

6. P. Shah, N. Raval, N. Shah J. Mater. Environ. Sci. 6, 2573-82 (2015)

7. A. Alzaydien American J. of Environm. Scien. 5 (3), 197-208 (2009)

8. M. Zankuli, H. Devlin, N. Silikas Dental Materials 30, 324-329 (2014)

9. M. Avdeev, N. Blagoveshchenskii, V. Garamus, A. Novikov, A. Puchkov Crystallography Reports 56, 1090-95 (2011)

10. D. Martemiyanov, A. Galanov, T. Yurmazova Fundamental research 8, 666-670 (2013) (in Russian)

11. G. Pushkareva, K. Kovalenko Mining Informational and Analytical Bulletin (scientific and technical journal) 9, 294-298 (in Russian) (2012)

12. E. Bannova, E. Zaloznaya, N. Kitaeva, S. Merkov, M. Muchkina, A. Chaban, A. Alekseev J. Water: chem. and ecology 11, 73-78 (2012) (in Russian)

13. V. Anisimov, K. Petrov, A. Ratnikov, P. Martynov, E. Podzorova, A. Chaban J. Water: chem. and ecology 10, 11-16 (2009) (in Russian)

14. A. Shilina, V. Milinchuk, E. Podzorova, P. Martinov, A. Chaban J. Water: chem. and ecology 11, 25-29 (2009) (in Russian)

15. Y. Pyatko, R. Akhmetova, A. Khatsrinov, V. Fakhrutdinova, A. Akhmetova, A. Gubaydullina Fundamental research 12, 320-324 (2015) (in Russian) 